\title{
PREFACE
}

\section{SEVEN CARDINAL SINS OF SCIENCE}

\author{
ALEKSANDER KOBYLAREK, \\ Institute of Pedagogy, University of Wrocław \\ J. Wł. Dawida 1, 50-527 Wrocław, Poland \\ e-mail address: aleksander.kobylarek@gmail.com
}

\begin{abstract}
This article tackles the issues associated with feudal science, which leads to the cultivation of pseudo-science, the creation of inadequate assessment criteria and inappropriate mechanisms in assisting the development of science. Some characteristic symptoms of this pathological system are presented and brought together as a coherent whole. Feudal science cannot be reformed, but must be replaced by a healthy system of funding and research management. Particular defence mechanisms should above all be a concentration on quality of research and engagement in international scientific co-operation, thus counter-balancing the feudal science system.
\end{abstract}

Key words: feudal science, pathologies in science, helping scientific development, Glasperlenspiel.

There are two basic strategies in creating models for the practice of science. One of them is the idealistic search for truth at all costs, by using all available sources, sacrificing health, risking life and investing the last penny. The other is a fight for power and influence, a kind of domination, leading to a peaceful and comfortable existence. We can call this the feudal strategy.

For young practitioners of science, beginning their adventures in research, it more often than not appears that only the first strategy exists, and that their personal success can be measured only by the appropriate quality of their achievements. After time, however, it turns out that they have to work long and hard for any significant results, and that their success is ephemeral and defined by the various councils, committees and assessment boards of the local scientific community. Ambiguous (and often hidden) assessment criteria create the impression that science has nothing to do with the first strategy, but is instead founded on various groups and clans of followers of the "correct" model of science and theory. For such communities (not to say cliques) it is not science which is important, but the exercising of control over those attempting to practice science.

The matter is further compounded by the fact that these pseudo authorities, who promote and support each other, have no idea what the practice of science involves, because they themselves have never achieved anything on an international level. Lack of foreign languages skills, publication restricted to a local - at most national - level, and a lack of contact with the wider scientific world (personal contact with fellow academics and familiarity with specialist literature), all mean that they can be an authority only to themselves, their colleagues, and students who are not aware of the situation. The latter 
have no chance of protesting when they come to writing their doctoral theses, and realise that going against the accepted ,"arrangements" would surely lead to ostracism, stigmatization and rejection, both on a personal level and regarding their work, which will be described as poor, full of methodological errors and in effect worthless. If we accept that within the feudal strategy significant scientific achievement depends on the judgement of the community, then rejection and ostracism are even more the result of the environmen$t^{\prime}$ s , arrangements', especially when it comes to gaining higher academic titles, because why should anybody who has proved their knowledge and methodological skills want to show that they are intellectually incompetent and unworthy of advancement?

Feudal science is burdened with many sins which can never lead to clear assessment criteria, even though this is one of the main factors of the pathology. Based on observation, conversations with doctoral students and associate professors in various European education institutes, as well as media reports and internet discussions, we can attempt to codify and define at least the most important symptoms of degeneration in the academic community. We can call then the Seven Cardinal Sins.

The fundamental problem would seem to be the dogma of the infallibility of the professor. In the world of feudal science it is the professor who decides what is the truth, correct methodology, innovation and discovery. Discussion of research results, methodological approach, selection of explanatory theories and results is only possible within strict limits. Young academics are unable to prove their correctness, or show the assessor's unfamiliarity with the subject or suggest that he lacks the necessary competence, because every member of the committee would immediately take offence and show their animosity towards the student candidate. Standing up for the truth and questioning the infallibility of the professor is equivalent to rudeness and lack of respect, which can lead to the student being assessed according to ethics unconnected with science, and always negatively. It doesn't matter that the candidate is right, but that "he showed no respect" by insulting the professor. The effect is the same as if the student was not right.

Another aspect of this problem is the expression of opinions outside the professor's own field of competence. Thus, a sociologist can hold forth on pedagogy and a historian can promote a pedagogic thesis, simply because he is a professor. This is not about interference when a particular issue may arouse the interest of several different disciplines, which is natural and something to be desired, but the evident crossing of boundaries between disciplines both in research problems and methodology. Consent to such a practice is only possible because nobody is able to question the competence of the feudal professor, not even other professors.

Connected with the infallibility of the professor is a power structure based on the pyramid. In such a model there are many humble people, largely unknown in the world of science, working for the few for whom an academic title opens the door to exercising authority. An extreme example of this abuse of power is the adding of the professor's name to the work of his students as co-author. By definition, the most highly honoured academics are predestined to fill the highest offices in the university and sit on the councils which decide on the bestowing of scientific credibility on their younger colleagues. Above all, it is the possession of an academic title which decides on a person's competence to govern and pass judgement and not, more appropriately, expert managerial competence. It is easy to imagine that in effect this often leads to blatantly unfair asses- 
sments or irrational administrative decisions. In such a structure, academic advancement is not the result of scientific achievement but down to contributions in other areas, such as administration, where young academics become dogsbodies burdened with the worst kind of administrative work on behalf of their patrons. Scientific achievement is even frowned upon if young academics are seen to be threatening the position of their superiors or, heaven forbid, they try to engage in any kind of discussion as an equal partner.

Unclear criteria for assessment and the sentences passed by feudal academics create a whole range of negative effects, which can lead to low social capital, one of the main defects of the system. This arises from an inability to construct real and permanent academic communities, a lack of trust in colleagues (especially those in close proximity), and meritorical tensions. In this last case, the practice of science becomes merely an instrument in achieving other goals. Young academics under pressure become accustomed to rivalry in the academic rat race. They not only lose their ability to co-operate, but in extreme cases hide their achievements from their colleagues in order to lull them into a false sense of security and prevent them from making a greater effort.

Admittedly we all count as individuals, but significant scientific achievement is only possible thanks to co-operation and common effort, often in large research groups. Attempting to practice science individually only leads us up a blind alley and a return to 19th century methods.

The above effects are magnified by disrupted communication. In the case of low social stock and a top to bottom power structure, a reluctance for academics to communicate with each other is natural. Scientific conferences are rarely events of any consequence and become merely a means of attestation or point scoring. Those at the top of the hierarchy use their position to put forward hypotheses without any backup, because nobody would dare to verify them publicly. Young academics often come up against ignorance and contempt as unworthy upstarts.

The bogus language of feudal science is full of cancers and absurdities which bring nothing new to our knowledge of the world, and which are treated by their creators with a reverence worthy of some Nobel discovery. In publications of doubtful merit, complicated language and elaborate vocabulary merely serve tp mask an intellectual void and a lack of original thought.

Fanciful language is to a certain extent one of the symptoms of an effect which we can regard as form over content. Other symptoms of this problem are a quantitative approach to the assessment of the value of scientific work, self-reference, and over-formulated criteria for assessment. On the one hand, innovation leads to elaborate language games to hide an intellectual void, but on the other hand it is difficult to assess poor science for innovation and originality when they are clearly not there. This leads to the invention of even more criteria for assessing scientific texts (number of characters, footnotes, bibliography, methodology), as long as it is not assessed for originality. On the other hand, texts which fulfil the various kinds of formal criteria have to be 'autoreferential', in other words they have to multiply to infinity the same idea, most often somebody else's put in different words. New ideas are in turn unacceptable because they upset the ordered world of existing scientific experts. Such ideas must be rejected because they would question the infallibility of the professor, and any kind of scientific revolution would be extremely unwelcome. 
The final effect is stagnation of the environment. Those who have authority in feudal education will only allow the propagation of those ideas which they were brought up on and thanks to which they attained their powerful position. They themselves show a permanent inability to learn, ignorance and stagnation, and they present an insurmountable obstacle for their successors. According to the scientific establishment, the ideal candidate is "passive, average and obedient", or at least clever at presenting well-worn ideas to his feudal masters. These characteristics, however, guarantee oblivion in world science, which is constantly seeking new inspiration.

The final sin of feudal science is emotionalism. Feudal science is not guided by rational argument but by emotion. When it comes to assessing scientific work, doctoral theses or articles, the victim never knows how or why he has failed. It can even happen that, as a result of a negative assessment, there is animosity between the professor and somebody close to them who is being assessed - a work colleague, a superior or a co-author. Sometimes an "inappropriate" construction in an article results in offence and resentment towards the author for many years. This is mainly the result of a sense of non-appreciation amongst feudal academics. They know very well that their scientific work has no significant meaning, so any attempt to show that the king has no clothes is an attack on their misunderstood freedom of research. On every level we are dealing with a sense of impotency, irrelevance and non-appreciation. This can be seen in the aggressive comments on scientific internet forums, the somatically and psychological illnesses associated with climbing the academic career ladder, and a permanent lowering of spirit bordering on depression. In fact, it seems we can coin a new term which is characteristic of feudal science - scientific depression.

Is it possible to reform feudal science? The observations presented here would seem to point to a bitter conclusion that any kind of attempt at reform doesn't make much sense. Instead, we should try to identify the extent of feudalism and replace it with a healthy mechanism for practicing science with idealistic motives.

This does not mean, of course, that 'idealistic motives' means underfunding.

It is far worse when the whole science system, or a particular area of it, is feudal. In that case, it would be necessary to change the whole system, or relationships within a given discipline, by introducing new principles for its functioning. Such a reform, despite the views of some "specialists" in higher education and science, should be initiated, introduced and strictly controlled by the beneficiaries of the education system. However, without reform the practice of science will become merely an artful 'Glasperlenspiel' (a game with glass beads). In this process, chosen academics can only be advisors, not decision makers. Additionally, a policy of limited trust should be applied to those involved with feudal science.

Changes to the system at the level of the individual researcher are impossible to introduce. So what can we, as young academics observing the symptoms of feudalism around us, do? Believe, fight, never give in, and create our own academic community based on healthy assessment criteria, far from feudalism and pathology. Polemicise and condemn pseudo-science and stagnation. Be indefatigable in the practice of science, returning to the heart of the matter. Create transnational interdisciplinary communities which unite us in the proper practice of science. 